REPLY

\section{Surgical device-enabled epicardial LAA closure to achieve safe, complete, and durable LAA occlusion}

\author{
Etem Caliskan, James L. Cox, Volkmar Falk, Sacha P. Salzberg \\ and Maximilian Y. Emmert
}

We thank our colleagues Hui and Lee for their Correspondence (Mechanical occlusion of the left atrial appendage - lessons from surgical experience. Nat. Rev. Cardiol. https://doi.org/10.1038/nrcardio.2018.7; $2018)^{1}$ on our Review (Caliskan, E. et al. Interventional and surgical occlusion of the left atrial appendage. Nat. Rev. Cardiol. 14, 727-743; 2017) $)^{2}$. Indeed, including in our Review an analysis of particular failure modes of different left atrial appendage (LAA) closure techniques and devices would have been interesting, but was beyond the scope of our article. We acknowledge the considerations by Hui and Lee on the anatomical and procedural complexities of achieving complete LAA closure, which is, however, also mentioned in our Review.

Second, we respectfully disagree with the authors' statements and opinion regarding the AtriClip ${ }^{1}$. Our overall conclusions and confidence in the AtriClip device are not only drawn from the referenced study ${ }^{3}$, but are also based on numerous preclinical and clinical studies that have systematically evaluated the AtriClip for its safety and efficacy profile over the past decade $\mathrm{e}^{4-7}$. Indeed, initial experiences from our own first-in-human pilot trial ${ }^{7}$ and the multicentre EXCLUDE trial $^{4}$ with systematic imaging follow-up (either transoesophageal echocardiography (TEE) or CT imaging) clearly demonstrated the safety and efficacy of the AtriClip. These findings were further validated in our 3-year CT-imaging follow-up report showing the stability and durability of the AtriClip, with no thrombus formation at the stump ${ }^{5}$. Moreover, a study published in 2017 including 101 patients with a follow-up of $18 \pm 11$ months using TEE or CT further confirmed these results ${ }^{6}$. Importantly, these studies also highlight that AtriClip-enabled LAA closure is durable when complete TEE-guided occlusion is achieved intraoperatively.

In the referenced study from our centre (which also states the potential limitations of the study) $)^{3}$, we have further validated the long-term safety, efficacy, and durability of the AtriClip in an additional large cohort (including the first-in-human trial cohort and all consecutive patients thereafter). Notably, neither in this study ${ }^{3}$ nor in our ongoing clinical programme have we ever experienced any impairment of the circumflex artery while achieving complete LAA closure with the AtriClip. On the basis of this continuously increasing and supporting evidence on the AtriClip (with currently $>100,000$ devices sold and applied worldwide), we strongly advocate for a device-enabled epicardial closure strategy to achieve safe, complete, and durable LAA closure.

Third, we generally agree with the comment by Hui and Lee on the importance of a residual stump after surgical LAA closure and, in accordance with current clinical recommendations, the maximum stump length should not exceed $10 \mathrm{~mm}$ (REFS 8-11). However, we consider this cut-off to be a threshold, and we aim in all our patients to stay substantially $<10 \mathrm{~mm}$ or to have no stump at all. Indeed, brief preliminary analysis of our patients with available CT data (which is part of an ongoing separate study) shows that the majority of patients $(>70 \%)$ present with no detectable stump, whereas the rest present with a stump length substantially $<10 \mathrm{~mm}$. Importantly, we want to highlight that the AtriClip-enabled LAA closure creates an almost smooth line of occlusion by endocardial adaptation if applied appropriately. We and others have demonstrated this mode of closure in preclinical studies ${ }^{12-14}$. As such, the thrombogenicity profile of this AtriClip-enabled closure cannot be directly compared with a true cul-de-sac, as seen after sutured or ligated LAAs as reported by Hui et al. ${ }^{15}$. Additionally, and as per definition, the ostium and the neck of the LAA do not contain pectinate muscles and, therefore, can be considered fairly safe with regard to thrombogenicity ${ }^{10}$. We, however, share the authors' opinion that clear recommendations on cessation of oral anticoagulant therapy after LAA closure are urgently needed.
Finally, we respectfully disagree that we might have neglected to mention contemporary papers in our Review. The mentioned randomized clinical pilot trial (authored Lee) including 28 patients demonstrated that stapled excision, surgical excision, and surgical ligation of the LAA are associated with highly heterogeneous success rates and come with different modes of failure ${ }^{16}$. However, because these results have been known for more than a decade $e^{8,17-19}$, we did not consider these findings to add any substantial new information to the contemporary field of surgical LAA closure.

Etem Caliskan and Volkmar Falk are at the Department of Cardiovascular Surgery, Charité Universitätsmedizin Berlin, Berlin, Germany, and at the Department of Cardiothoracic and Vascular Surgery, German Heart Institute Berlin, Berlin, Germany.

James L. Cox is at the Feinberg School of Medicine, Northwestern University, Chicago, IL, USA.

Sacha P. Salzberg is at the HeartClinic, Hirslanden Hospital, Zurich, Switzerland.

Maximilian Y. Emmert is at the Clinic for Cardiovascular Surgery, University Hospital Zurich, University of Zurich, Zurich, Switzerland.

Correspondence to M.Y.E. maximilian.emmert@usz.ch doi: 10.1038/nrcardio.2018.8 Published online 13 Feb 2018

Hui, D. S. \& Lee, R. Mechanical occlusion of the left atrial appendage - lessons from surgical experience. Nat. Rev. Cardiol. https://doi.org/10.1038/ nrcardio.2018.7 (2018).

2. Caliskan, E. et al. Interventional and surgical occlusion of the left atrial appendage. Nat. Rev. Cardiol. 14, 727-743 (2017)

3. Caliskan, E. et al. Epicardial left atrial appendage AtriClip occlusion reduces the incidence of stroke in patients with atrial fibrillation undergoing cardiac surgery. Europace https://doi.org/10.1093/europace/ eux211 (2017)

4. Ailawadi, G. et al. Exclusion of the left atrial appendage with a novel device: early results of a multicenter trial. J. Thorac. Cardiovasc. Surg. 142, 1002-1009.e1 (2011)

5. Emmert, M. Y. et al. Safe, effective and durable epicardial left atrial appendage clip occlusion in patients with atrial fibrillation undergoing cardiac surgery: first long-term results from a prospective device trial. Eur. J. Cardiothorac. Surg. 45, 126-131 (2014).

6. Kurfirst, V., Mokracek, A., Canadyova, J., Frana, R. \& Zeman, P. Epicardial clip occlusion of the left atrial appendage during cardiac surgery provides optimal surgical results and long-term stability. Interact. Cardiovasc. Thorac. Surg. 25, 37-40 (2017).

7. Salzberg, S. P. et al. Left atrial appendage clip occlusion: early clinical results. J. Thorac. Cardiovasc. Surg. 139, 1269-1274 (2010).

8. Kanderian, A. S., Gillinov, A. M., Pettersson, G. B. Blackstone, E. \& Klein, A. L. Success of surgical left atrial appendage closure: assessment by transesophageal echocardiography. J. Am. Coll. Cardiol. 52, 924-929 (2008).

9. Mokracek, A. et al. Thoracoscopic occlusion of the left atrial appendage. Innovations 10, 179-182 (2015).

10. Aryana, A. et al. Association between incomplete surgical ligation of left atrial appendage and stroke and systemic embolization. Heart Rhythm 12, 1431-1437 (2015)

11. Healey, J. S. et al. Left Atrial Appendage Occlusion Study (LAAOS): results of a randomized controlled pilot study of left atrial appendage occlusion during coronary bypass surgery in patients at risk for stroke. Am. Heart J. 150, 288-293 (2005). 


\section{CORRESPONDENCE}

12. Fumoto, H. et al. A novel device for left atrial appendage exclusion: the third-generation atrial exclusion device. J. Thorac. Cardiovasc. Surg. 136 , 1019-1027 (2008).

13. Salzberg, S. P. et al. Surgical left atrial appendage occlusion: evaluation of a novel device with magnetic resonance imaging. Eur. J. Cardiothorac. Surg. 34, 766-770 (2008)

14. Sunagawa, G., Karimov, J. H., Breitbach, M. Robinson, N. A. \& Fukamachi, K. Impact of a refined advanced design for left atrial appendage exclusion. Eur. J. Cardiothorac. Surg. 52, 1098-1103 (2017)

15. Hui, D. S., Alderson, L. J. \& Lee, R. Left atrial appendage thrombus after successful surgical exclusion on anticoagulation: a need for closer postintervention monitoring. Ann. Thorac. Surg. 98, 1478 (2014).

16. Lee, R. et al. A randomized, prospective pilot comparison of 3 atrial appendage elimination techniques: internal ligation, stapled excision, and surgical excision. J. Thorac. Cardiovasc. Surg. 152, 1075-1080 (2016)

17. Dawson, A. G., Asopa, S. \& Dunning, J. Should

patients undergoing cardiac surgery with atrial fibrillation have left atrial appendage exclusion? Interact. Cardiovasc. Thorac. Surg. 10, 306-311 (2010).

18. García-Fernández, M. A. et al. Role of left atrial appendage obliteration in stroke reduction in patients with mitral valve prosthesis: a transesophageal echocardiographic study. J. Am. Coll.Cardiol. 42, 1253-1258 (2003).

19. Katz, E. S. et al. Surgical left atrial appendage ligation is frequently incomplete: a transesophageal echocardiographic study. J. Am. Coll. Cardiol. 36 , 468-471 (2000)

\section{Competing interests}

J.L.C. is a consultant for and holds shares in Atricure and SentreHEART. S.P.S. and M.Y.E. have received speaker fees from Atricure and Maquet. E.C. and V.F. declare no competing interests. 